\title{
TITLE:
}

\section{Obtaining secure stapling of a double stapling anastomosis.}

$\operatorname{AUTHOR}(\mathrm{S}):$

Nakayama, Shinya; Hasegawa, Suguru; Hida, Koya; Kawada, Kenji; Sakai, Yoshiharu

\section{CITATION:}

Nakayama, Shinya ...[et al]. Obtaining secure stapling of a double stapling anastomosis.. The Journal of surgical research 2015, 193(2): 652-657

ISSUE DATE:

2015-02

URL:

http://hdl.handle.net/2433/193277

\section{RIGHT:}

(C) 2015 Elsevier Inc:; This is not the published version. Please cite only the published version.; この論文は出版社版でありません。引用の際に は出版社版をご確認ご利用ください。 


\section{Revised: August 1, 2014}

\section{Obtaining secure stapling of a double stapling anastomosis}

Shinya Nakayama* M.D., Suguru Hasegawa* M.D., Ph.D., FACS, Koya Hida M.D., Ph.D., Kenji Kawada M.D., Ph.D., Yoshiharu Sakai, M.D., Ph.D., FACS

*These two authors contributed equally to this work.

Department of Surgery, Kyoto University Graduate School of Medicine 54 Shogoin-Kawaharacho, Sakyo, Kyoto 606-8507, JAPAN

Short title: Secure stapling in DST

Disclosures: Shinya Nakayama received financial and technical support to perform the experiment by Ethicon Endo-Surgery. Kenji Kawada, Koya Hida, Suguru Hasegawa, and Yoshiharu Sakai have no conflicts of interest or financial ties to disclose.

Authors' contributions

Study design: Koya Hida, Suguru Hasegawa, Shinya Nakayama

Data collection: Shinya Nakayama, Suguru Hasegawa

Analysis and interpretation: Suguru Hasegawa, Kenji Kawada, Koya Hida

Writing the manuscript: Suguru Hasegawa, Shinya Nakayama, Kenji Kawada

Critical revision of the manuscript: Yoshiharu Sakai

Correspondence:

Suguru Hasegawa

Department of Surgery

Kyoto University Graduate School of Medicine

54 Shogoin-Kawaharacho, Sakyo, Kyoto 606-8507, JAPAN

Email: shase@kuhp.kyoto-u.ac.jp

TEL: 81-75-366-7595 FAX: 81-75-366-7642 


\section{Abstract}

Background: Anastomotic leakage is a serious complication after rectal surgery. The aim of this study was to assess the effect of waiting time during firing of stapling devices on optimal staple formation.

Methods: An endoscopic linear stapler (ECHELON FLEX 60 ENDOPATH) with either a $60 \mathrm{~mm}$ blue or gold cartridge was applied to the cardiac and pyloric portions of 27 fresh porcine stomachs. Three different waiting times were used for the precompression and interstroke periods (precompression/interstroke: 0/0, $2 / 0$ and $2 / 2$ minutes). The staple line was divided into 4 portions (oral/anal and top/base), and the shape of each staple was evaluated. Optimal staple formation was also assessed using the circular stapler ( $\mathrm{CDH} 29)$.

Results: Mean thickness of the cardiac and pyloric portions was $2.4 \pm 0.35 \mathrm{~mm}$ and $4.0 \pm 0.4 \mathrm{~mm}$, respectively. The waiting time improved optimal staple formation for the blue cartridge, especially when it was used for the pyloric portion. Staple malformation was observed more commonly in the top portion than in the base portion; however, the former was improved by an interstroke waiting time. Staple formation using the circular stapler was satisfactory and not influenced by the pre-firing waiting time or tissue thickness.

Conclusion: Employment of a waiting time improves optimal staple formation when the endoscopic linear stapler is used for challenging tissue.

Keywords: Complication, Stapler, Anastomotic leakage 


\section{Introduction}

Double stapling technique (DST) anastomosis is a standard reconstructive procedure in low anterior resection of rectal cancer. Despite advances in operative devices and techniques, anastomotic leakage remains a serious postoperative complication after DST, with a reported incidence of $1-21 \%^{1}$. The cause is multifactorial, but ischemia and mechanical/tissue-related causes are two major concerns.

Appropriate selection and usage of the stapling device is necessary to obtain a strong staple line and secure intestinal closure. We previously reported that an adequate precompression time improved staple formation when a precompression type linear stapler (Endopath ETS-Flex 45) was applied to thick, challenging tissue ${ }^{2}$. Furthermore, we recently clarified that precompression time before firing was associated with anastomotic leakage after laparoscopic low anterior resection ${ }^{3}$. The ETS-Flex stapler has been since been replaced by the Echelon Flex stapler in clinical practice. Because the Echelon Flex stapler has a different stapling mechanism from that of the Endopath ETS Flex stapler, the aim of the present study was to examine the effect of a waiting time on optimal staple formation in DST when employing commonly used linear and circular endoscopic staplers. 


\section{Methods}

\section{Tissue}

A total of 27 porcine stomachs excised from Clawn miniature swines (age 20-25 weeks, weight approximately $30 \mathrm{~kg}$ ) were used in this study. The thickness of the stomach wall was measured at the cardiac and pyloric portions using a digital caliper (Mitutoyo Co., Kanagawa, Japan) as described previously².

\section{Endoscopic linear stapler}

We first evaluated the staple formation of the Echelon Flex 60 Endopath stapler with blue (3.5 mm staple leg length, $1.5 \mathrm{~mm}$ closed staple height) and gold (3.8 $\mathrm{mm}$ staple leg length, $1.8 \mathrm{~mm}$ closed staple height) cartridges (Ethicon Endo Surgery Inc., Cincinnati, $\mathrm{OH}$ ). The stapler was applied to the cardiac and pyloric portions of the stomach in either a straight or full-articulated position (Figure 1). We used 3 patterns of firing according to the precompression and interstroke waiting times (Figure 1). Precompression time was defined as the time from closing the jaws until starting the firing, and interstroke waiting time was defined as the waiting time after each stroke (3 strokes in total). The staple line was divided at its center to separate the top and base portions, and the shape of the staple in each area was assessed individually.

\section{Circular stapler}

Next, we evaluated the factors associated with optimal staple formation when using a circular stapler (CDH 29 Proximate ILS Curved Intraluminal Stapler, Ethicon Endo Surgery). Both simple anastomosis and double stapling technique anastomosis were performed (Figure 2). The cardiac or pyloric portion was opened, and the trocar of the circular stapler was brought out from the mucosal to serosal side. In the DST model, the stomach was divided using the Echelon stapler with a gold reload as in the previous experiment, the stapled part of the stomach was opened, and the trocar of the circular stapler was brought out from the mucosal side through the staple line (Figure 2). The anvil was passed through the stomach wall and connected to the trocar. Before firing, the stapler was closed in half or full position $(1.8$ or $1.0 \mathrm{~mm}$ closed staple height, respectively), and held for 0 or 2 minutes. 
The shape of the staple was assessed as previously described. A nylon sheet was placed on the anvil side to maintain the same staple alignment that was produced at the time of anastomosis.

\section{Evaluation of staple formation}

Staples were extracted after the stapled tissue was dissolved using CLEAN K-200 (CLEAN Chemical Co., Osaka, Japan). The shape of each staple was classified as either optimal or suboptimal as described previously². Essentially, optimal staples were in a closed staple position, while suboptimal staples were in an open position. The optimal staple formation rate was defined as the number of optimally shaped staples divided by the total number of staples in each area. We also investigated factors that might influence the optimal staple formation rate, namely, precompression and interstroke waiting times, tissue thickness, and location (top or base) of the cartridge.

\section{Statistical analysis}

Results are presented as the mean and standard deviation unless otherwise stated. The continuous variable (optimal staple formation ratio) was compared between groups using an unpaired t-test, Mann-Whitney test, or Kruskal-Wallis test (followed by the multiple comparison test). All statistical analysis was performed using JMP Pro 11.0 software (SAS Institute, Cary, NC). A p value less than 0.05 was considered statistically significant. 


\section{Results}

\section{Thickness of porcine stomach}

The mean thickness of the porcine stomach was $2.4 \pm 0.35 \mathrm{~mm}$ in the cardiac portion and $4.0 \pm 0.4 \mathrm{~mm}$ in the pyloric portion. As a reference, the thickness of the human rectum measured in the same manner was similar, at $4.45 \mathrm{~mm}$ (range $3.2-7.0 \mathrm{~mm}, \mathrm{n}=33$ ).

\section{Echelon stapler}

The total number of staples examined was 2479. The total optimal staple formation rate of the blue and gold cartridges was $84.0 \%$ and $93.8 \%$, respectively (Table 1). The shaft angle did not influence optimal staple formation, irrespective of the cartridge used or portion of the stomach. The optimal staple formation rate in the pylorus (83.7\%) was worse than that in the cardiac portion (93.0\%). The employment of a waiting time improved optimal staple formation (Table 1) and the difference was more prominent when using the blue cartridge (Figure 3a). Although usage of the gold cartridge was associated with a satisfactory overall staple formation rate (93\%), it was improved by adding an interstroke waiting time when applied to the pyloric portion (Figure 3b). When the blue reload was used at the pyloric portion, the staple formation rate at the base portion was improved by a precompression time, while the staple formation rate at the top portion was improved by an interstroke waiting time (Figure 4).

\section{Circular stapler}

The optimal staple formation rate was satisfactory $(100 \%)$ irrespective of waiting time before firing, anvil closure position, or type of anastomosis (DST or simple anastomosis) (Figure 5). 


\section{Discussion}

This study showed that precompression and interstroke waiting times improved staple formation when using the linear stapler for challenging tissue, but such an effect was not observed when using the circular stapler.

Staple malformation may cause insufficient tissue closure leading to staple line leakage. Despite improvements in stapling devices, proper selection and usage are necessary to obtain optimal results ${ }^{4}$. Although the exact causes of staple malformation are not fully understood, deviation of the staple legs due to tissue extrusion when piercing the tissue is a possible reason. Deviation of the staple leg would be more pronounced with thicker tissues. Tissue-device interaction is very important in tissue stapling ${ }^{5-7}$. Because the tissue consists of solid and liquid components, an appropriate length of compression before firing allows for fluid extrusion from the tissue. This may explain the better staple formation achieved after a waiting period and appropriate tissue compression.

Recently, we clarified that employing a precompression time was one of the factors associated with reducing anastomotic leakage after laparoscopic low anterior resection ${ }^{3}$. Although it is difficult to examine the shape of staples in the rectal stump in situ, we believe that the findings of this study indirectly indicate the effectiveness of employing a precompression time to enhance the mechanical strength of the staple line by optimizing the staple shapes.

Interestingly, staple formation at the top side of the cartridge was improved by an interstroke waiting time, especially when the stapler was used with thick tissues. This finding was consistent with our previous result using the ETS stapler ${ }^{2}$. The Echelon stapler has a unique E-beam mechanism that allows additional compression on the top side, especially in the case of thick tissue ${ }^{8}$. We believe that an interstroke waiting time improved staple formation by enhancing this effect in thick tissue at the top side of the cartridge.

Although appropriate selection of the cartridge is important for an optimal result, it is not always easy to determine tissue thickness intraoperatively ${ }^{9}$. Moreover, the manufacturer's recommended tissue thickness ${ }^{8}(1.8 \mathrm{~mm}$ when compressed, using the gold cartridge) is not always practical in the clinical setting, especially when stapling thick tissue such as the rectum. Despite suboptimal cartridge selection, staple formation was improved by employing a 
waiting time.

In contrast to the linear stapler, the circular stapler produced stable staple formation, irrespective of tissue thickness or degree of tissue compression. This might be due to the difference in the mechanism of stapling between linear and circular staplers. The tissue is stapled and divided simultaneously by circular staplers, and tissue extrusion is unlikely (parallel compression mechanism). The effect of a waiting time will also depend on the stiffness of the stapling instruments; stiffer stapling instruments will be less affected by the waiting period. Optimal staple formation was observed even at the crossing point between the circular and linear staplers in the double stapling technique mode ${ }^{10}$.

A limitation in this study is that we examined staple formation alone and not bleeding, blood supply ${ }^{11}$, tissue damage, or mechanical strength (bursting pressure) of the staple line ${ }^{12,13}$. Despite this drawback, we believe that this study provides useful information on appropriate usage of stapling devices.

\section{Conclusion}

The employment of a waiting period during firing reduced staple malformation when using the Echelon Flex 60 Endopath stapler for challenging tissue. 


\section{Figure Legends}

Figure 1. The endoscopic linear stapler was applied (a) to the cardiac and pyloric portions of the stomach, (b) using 3 patterns of firing, and (c) according to the precompression (T1) and interstroke waiting times (T2-4).

Figure 2. The stomach was (a) divided using the linear stapler, the stapled part of the stomach was opened, and (b) the trocar of the circular stapler (CDH 29) was brought out from the mucosal side through the staple line. (c) The anvil was passed through the stomach wall and connected to the trocar. Before firing, the stapler was closed in a half or full position, and held for 0 or 2 min. (d) Simple anastomosis.

Figure 3. a) Optimal staple formation rate according to waiting time in all portions. Employment of a waiting time improved staple formation, especially when using the blue cartridge. b) When confined in the pyloric portion, the improvement was more prominent and a significant difference was observed even when the gold cartridge was used. The $p$ value was calculated by Wilcoxon signed-rank test and error bars express standard error of the mean (SEM). ${ }^{*} \mathrm{P}<0.05$, multiple comparison test.

Figure 4. Optimal staple formation rate using the blue cartridge in the pyloric portion. Staple formation at the base portion of the cartridge was improved by employment of a waiting time before firing, and staple formation at the top portion was improved by an interstroke waiting time.

Figure 5. Staple formation using the circular stapler (DST model). Arrows indicate the crossing point of the staple line between the linear and circular staplers. 


\section{References}

1. Cong ZJ, Hu Lh Fau - Bian Z-Q, Bian Zq Fau - Ye G-Y, et al. Systematic review of anastomotic leakage rate according to an international grading system following anterior resection for rectal cancer.

2. Nakayama S, Hasegawa S, Nagayama S, et al. The importance of precompression time for secure stapling with a linear stapler. Surg Endosc 2011;25:2382-6.

3. Kawada K, Hasegawa S Fau - Hida K, Hida K Fau - Hirai K, et al. Risk factors for anastomotic leakage after laparoscopic low anterior resection with DST anastomosis.

4. Offodile AC, 2nd, Feingold DL, Nasar A, Whelan RL, Arnell TD. High incidence of technical errors involving the EEA circular stapler: a single institution experience. J Am Coll Surg 2010;210:331-5.

5. Baker RS, Foote J, Kemmeter P, Brady R, Vroegop T, Serveld M. The science of stapling and leaks. Obes Surg 2004;14:1290-8.

6. Chekan E, Whelan RL, Feng AH. Device-tissue interactions: a collaborative communications system. Annals of surgical innovation and research 2013;7:10.

7. Astafiev G. Investigation process relating to tissue compression in suturing and. stapling apparatus: surgical stapler. Chirurgicheskiey Shivayushiye Apparaty 1967;7:10.

8. Manufacturer's instruction for use by Ethicon Endo-Surgery Inc., Cincinnati, $\mathrm{OH}$, USA.

9. Elariny H, Gonzalez H, Wang B. Tissue thickness of human stomach measured on excised gastric specimens from obese patients. Surgical technology international 2005;14:119-24.

10. Tang WH, Friess H. Ischemia and intersecting stapling: the Achilles' heel of problematic low rectal anastomoses. Tech Coloproctol 2013;17:463-4.

11. Morita K, Maeda N, Kawaoka T, et al. Effects of the time interval between clamping and linear stapling for resection of porcine small intestine. Surg Endosc 2008;22:750-6. 
12. Goto T, Kawasaki K, Fujino Y, et al. Evaluation of the mechanical strength and patency of functional end-to-end anastomoses. Surg Endosc $2007 ; 21: 1508-11$.

13. Kawasaki K, Fujino Y, Kanemitsu K, et al. Experimental evaluation of the mechanical strength of stapling techniques. Surg Endosc 2007;21:1796-9. 


\section{Figure 1}

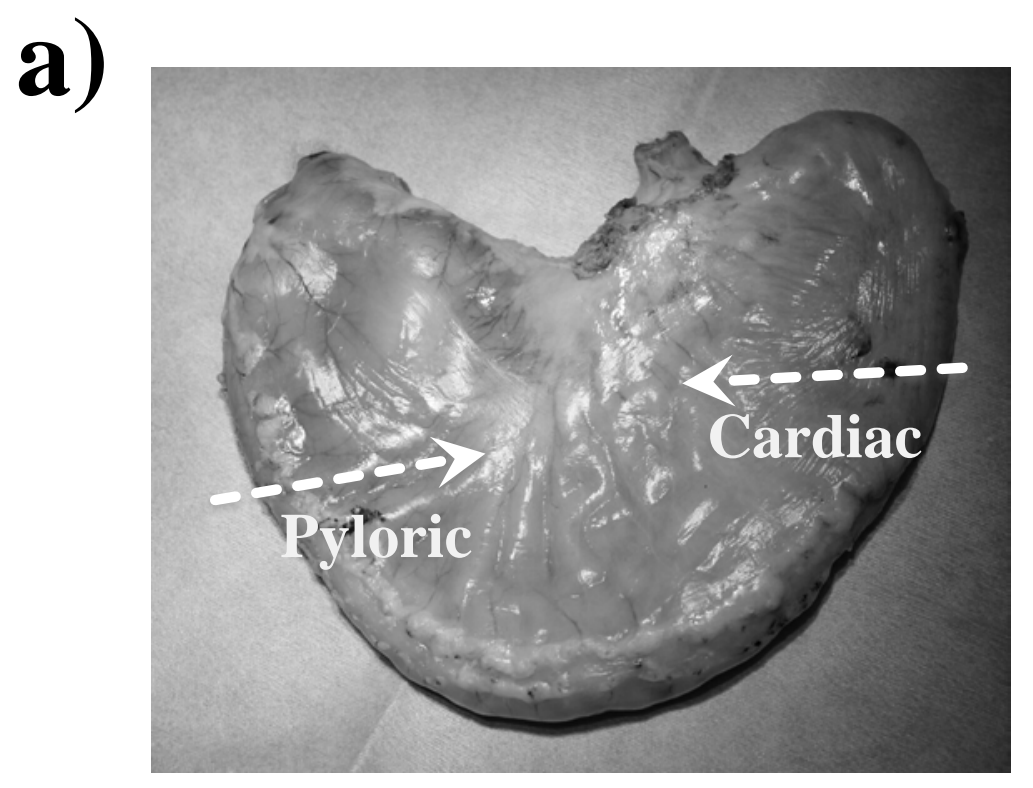

c)

b)

\begin{tabular}{|c|c|c|}
\hline & $\begin{array}{c}\text { T1 } \\
\text { (min) }\end{array}$ & $\begin{array}{c}\text { T2-4 } \\
\text { (min) }\end{array}$ \\
\hline Pattern 1 (0-0) & 0 & 0 \\
\hline Pattern 2 (2-0) & 2 & 0 \\
\hline Pattern 3 (2-2) & 2 & 2 \\
\hline
\end{tabular}

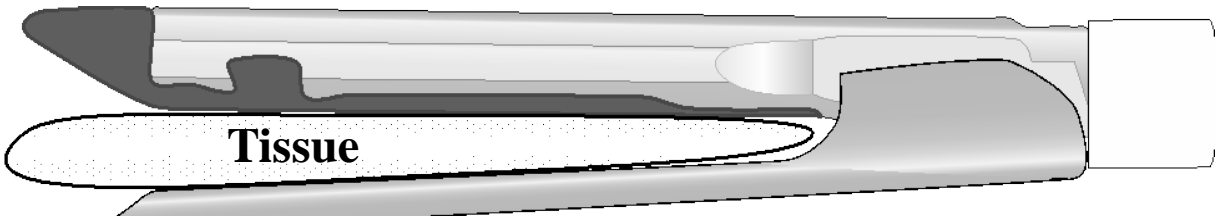

Precompression time (T1)

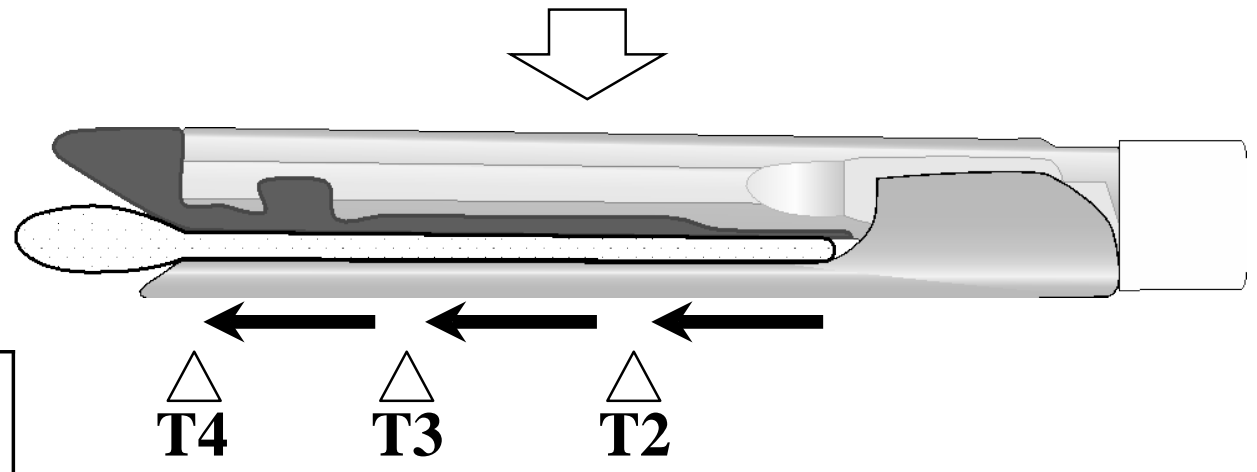

Interstroke waiting time (T2-4) 
Figure 2

a)
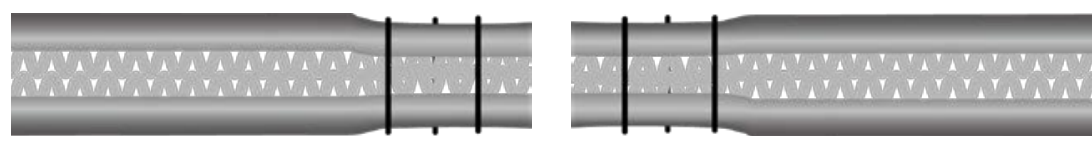

c)
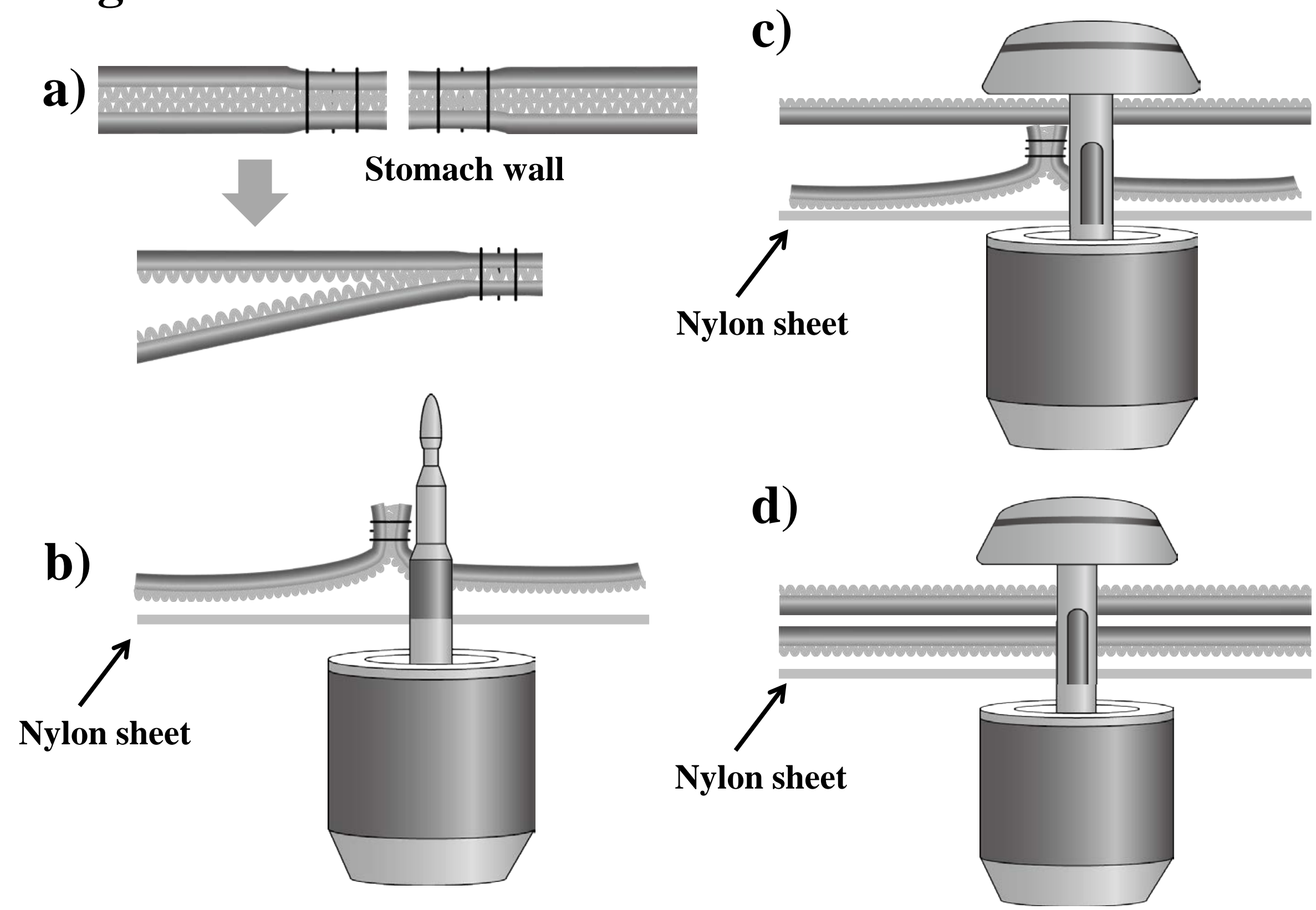

Nylon sheet 


\section{Figure 3}

a) All portions

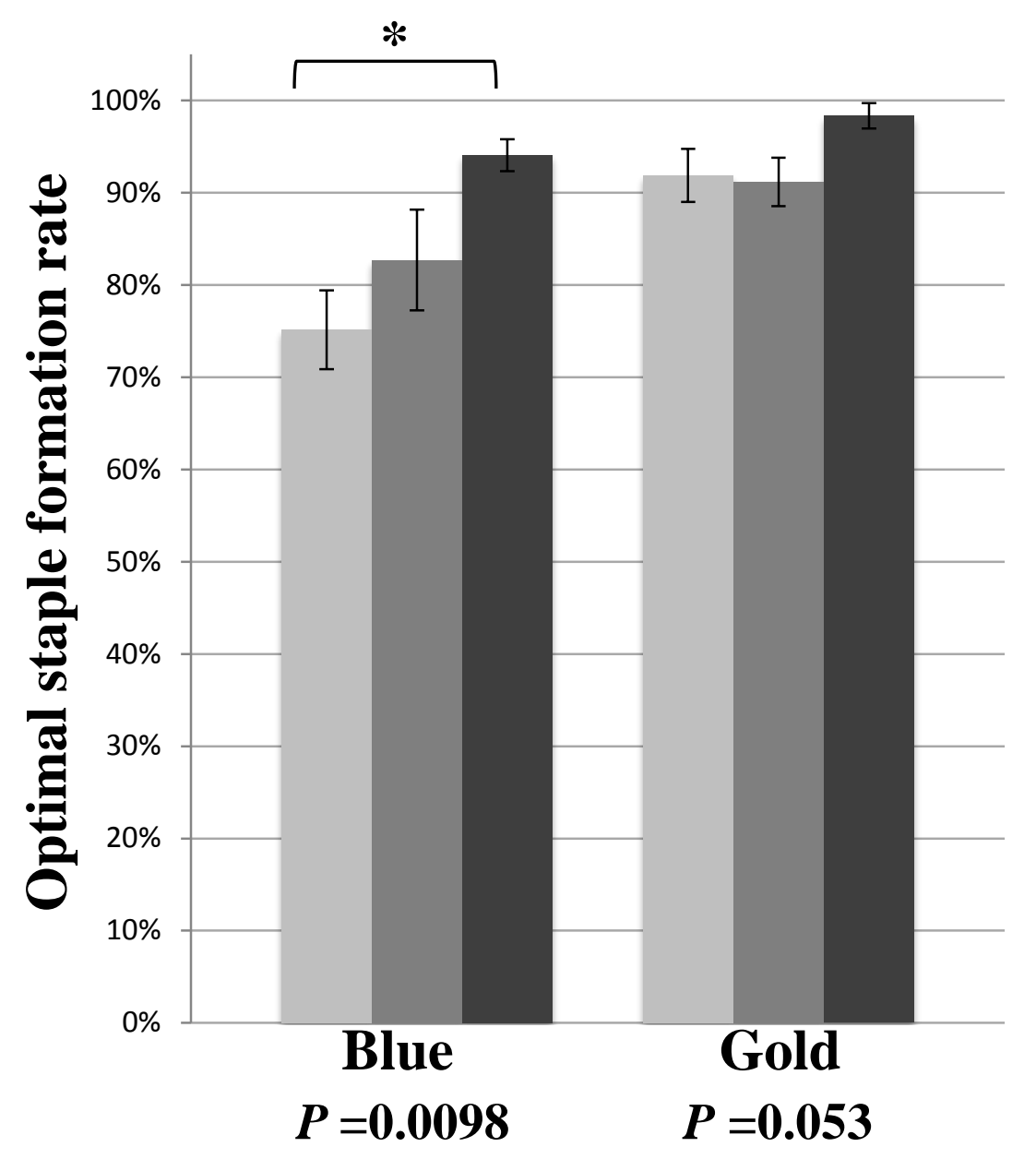

b) Pyloric

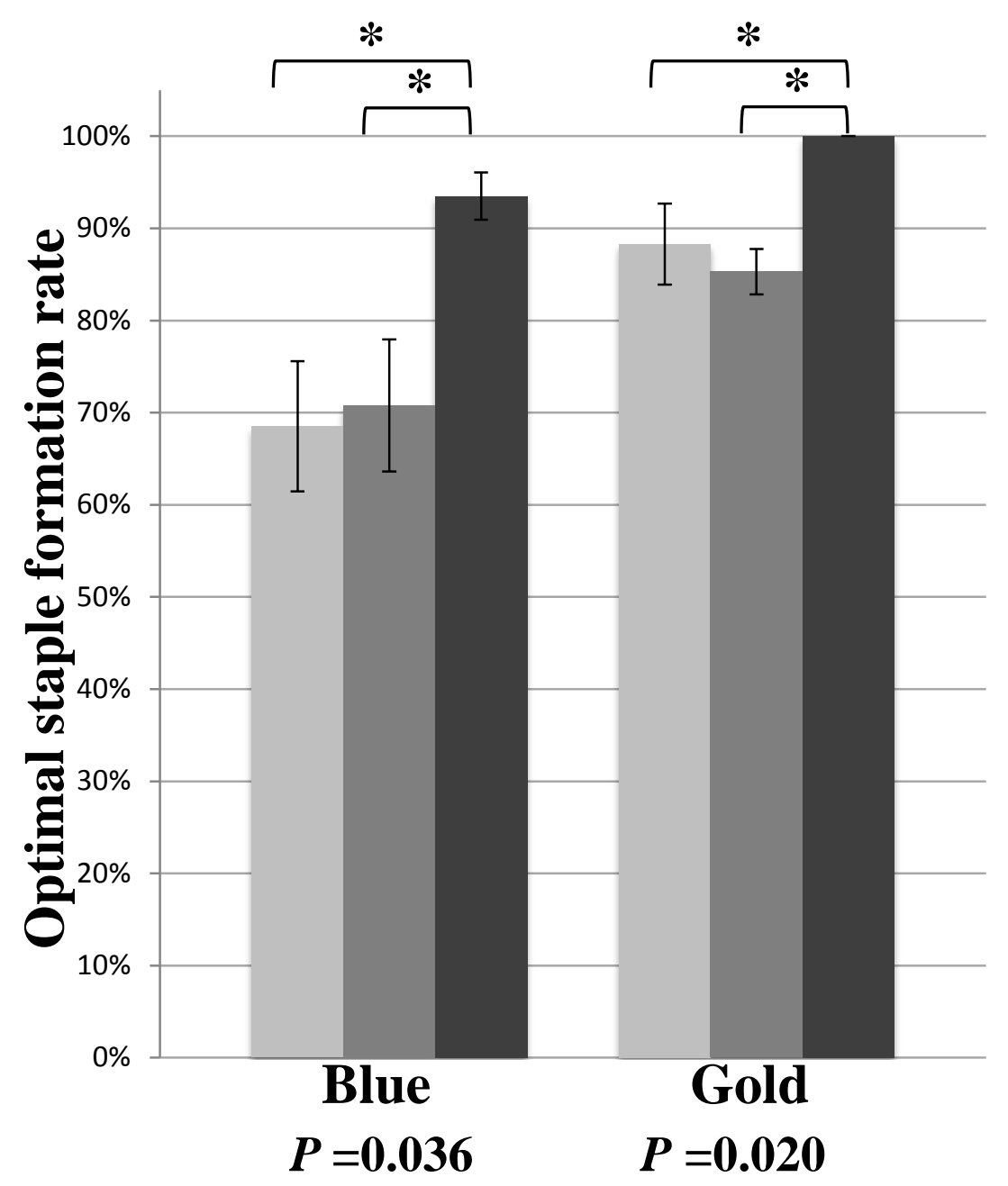

Waiting time (precompression-interstroke)

$\square 0-0 \square 2-0 \square 2-2$




\section{Figure 4}

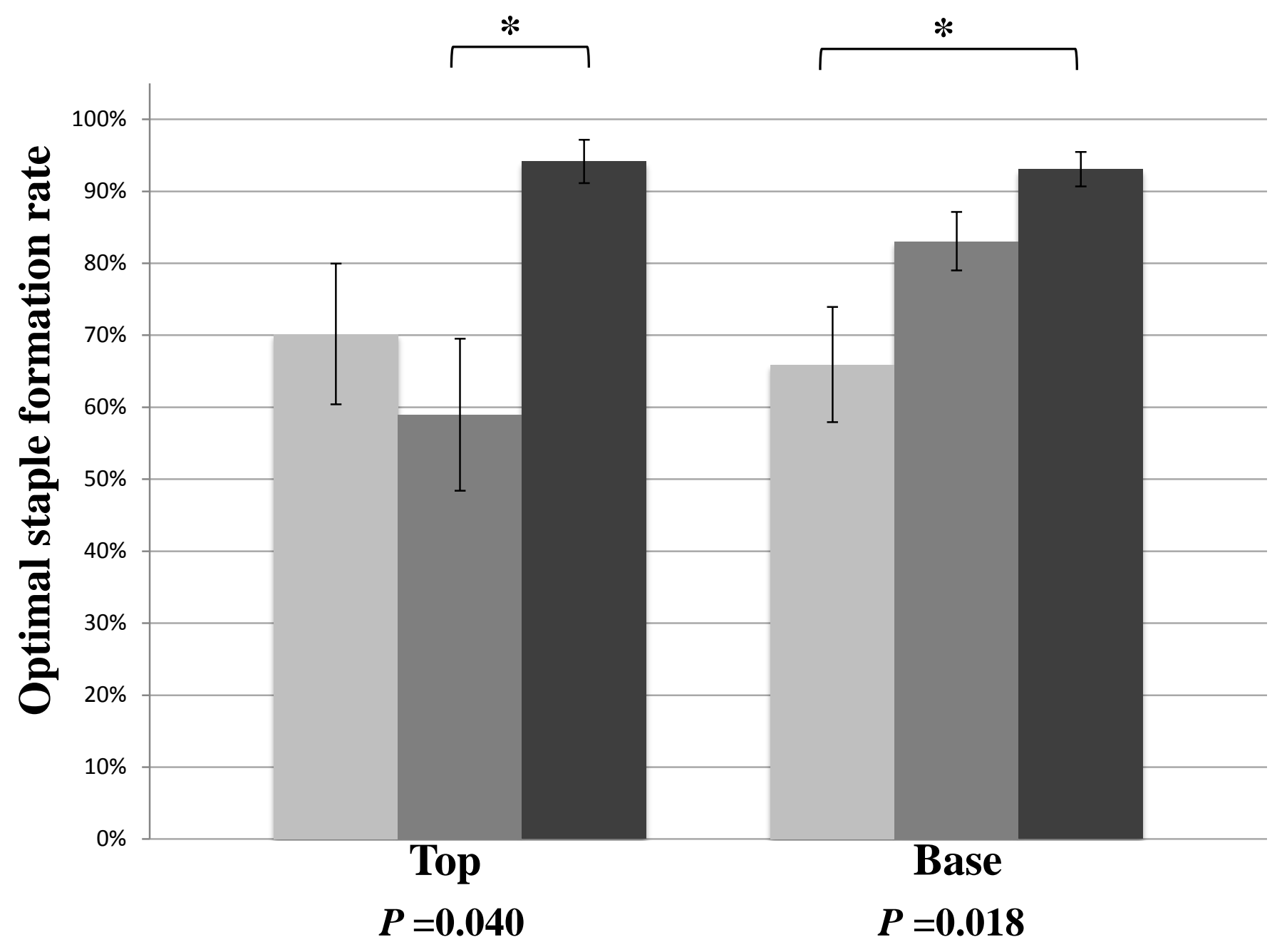

Waiting time (precompression-interstroke)

$0-0 \square 2-0 \square 2-2$




\section{Figure 5}

\section{Cardiac}

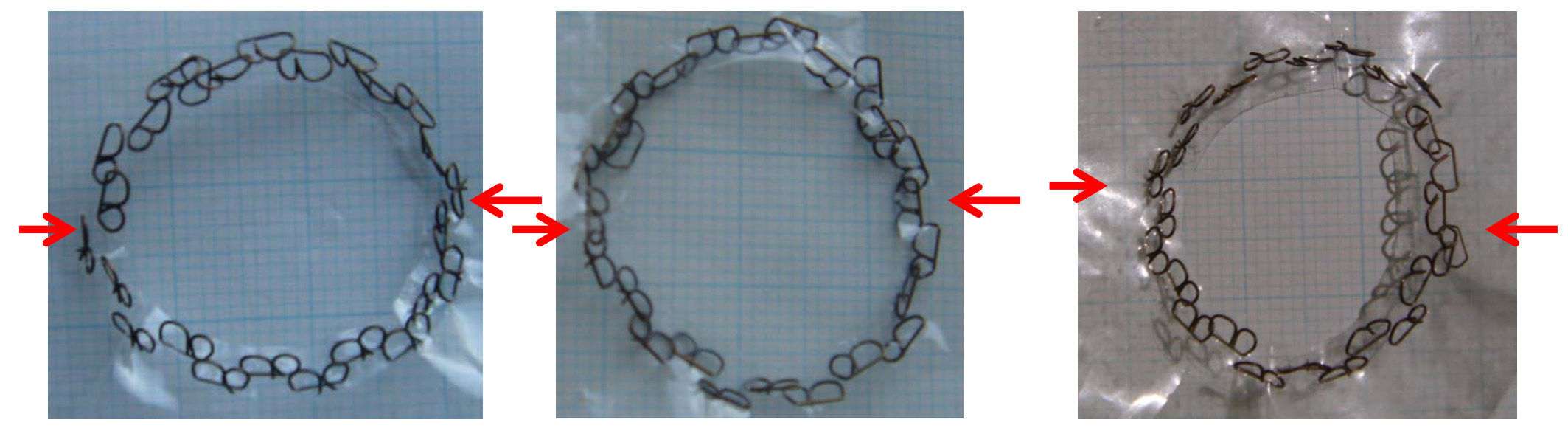

Pyloric

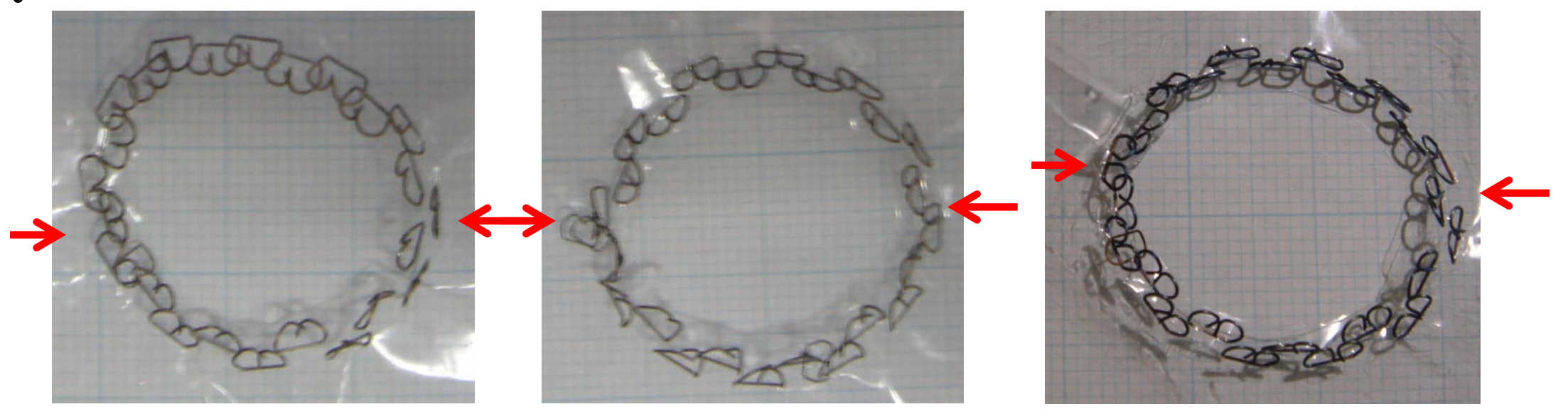

